\title{
Anemia in combined antiretroviral treatment-naive HIV-infected patients in China: A retrospective study of prevalence, risk factors, and mortality
}

\author{
Guorui Dai $^{1,2,}$, Jiang Xiao ${ }^{1, \S}$, Guiju Gao ${ }^{1}$, Xuejing Chong ${ }^{2,3}$, Fang Wang ${ }^{1}$, Hongyuan Liang ${ }^{1}$, \\ Liang $\mathrm{Ni}^{1}$, Di Yang ${ }^{1}$, Fengting $\mathrm{Yu}^{2}$, Ling $\mathrm{Xu}^{1,2}$, Di Wang ${ }^{2,3}$, Junyan Han ${ }^{2}$, Hui Zeng,* \\ Hongxin Zhao ${ }^{1, *}$ \\ ${ }^{1}$ The National Clinical Key Department of Infectious Diseases, Beijing Ditan Hospital, Capital Medical University, Beijing, \\ China; \\ ${ }^{2}$ Institute of Infectious Diseases, Beijing Ditan Hospital, Capital Medical University, Beijing, China; \\ ${ }^{3}$ The National Clinical Key Department of Infectious Diseases, Peking University Ditan Teaching Hospital, Beijing, China.
}

\begin{abstract}
Summary
Anemia is one of the most important complications of HIV infection. In China, the prevalence, risk factors, and association between anemia and prognosis in HIV-infected patients are poorly elucidated. We analyzed data from 3452 HIV-infected patients not yet on combined antiretroviral therapy (cART) attending Beijing Ditan Hospital from June, 2003 to December, 2015. The overall prevalence of anemia was $9.8 \%(7.6 \%$ mild, $1.9 \%$ moderate, and $0.2 \%$ severe anemia). Female sex (odds ratio $[O R]=3.71,95 \%$ confidence interval $[C I]: 1.46-6.51, p=0.003)$, age $40-59$ years $(\mathrm{OR}=\mathbf{2 . 5 4}, 95 \% \mathrm{CI}: 1.59-4.05, p<0.001)$, body mass index $<18.5 \mathrm{~kg} / \mathrm{m}^{2}(\mathrm{OR}=\mathbf{2 . 2 3}, 95 \% \mathrm{CI}: 1.31-3.79, p=0.003)$, baseline HIV RNA $>10^{5}$ copies $/ \mathrm{mL}(\mathrm{OR}=\mathbf{2 . 7 9}, 95 \%$ CI: $1.85-4.20, p<0.001)$, baseline CD4 count $\leq 50 \times 10^{9} / \mathrm{L}$ $(\mathrm{OR}=17.12,95 \%$ CI: 7.70-38.06, $p<0.001)$ and CD4 count 51-199 $\times 10^{9} / \mathrm{L}(\mathrm{OR}=\mathbf{2 . 8 1}, 95 \%$ CI: $1.32-5.99, p=0.007$ ) were risk factors for anemia. Age 40-59 years (adjusted hazard ratio $[\mathrm{AHR}]=5.76,95 \% \mathrm{CI}$ : $1.62-20.55, p=0.007)$, and anemia - mild $(\mathrm{AHR}=\mathbf{7 . 4 6 , 9 5 \%}$ CI: $1.48-37.50, p=0.015)$, moderate $(\mathrm{AHR}=9.89$, CI: $1.35-72.38, p=0.024)$, and severe $(\mathrm{AHR}=\mathbf{2 8 . 2 9}, \mathbf{9 5 \%} \mathrm{CI}: \mathbf{2 . 7 5 - 2 9 0 . 5 4}, \boldsymbol{p}=\mathbf{0 . 0 0 5})$ anemia - were associated with an increased hazard of death. In this cohort, mild anemia was most common. Anemia was associated with female sex, older age, lower body mass index, lower baseline CD4 count, and higher viral load. Moreover, anemia was associated with an increased risk of death. These findings should promote awareness among physicians to make a timely diagnosis of HIV and to help physicians prioritize prevention and intervention strategies for anemia in HIV-infected patients.
\end{abstract}

Keywords: HIV/AIDS, anemia, prevalence, mortality, risk factors

Released online in J-STAGE as advance publication November 26, 2016.

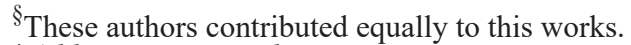

*Address correspondence to:

Dr. Hongxin Zhao, The National Clinical Key Department of Infectious Diseases, Beijing Ditan Hospital, Capital Medical University, No.8 Jingshun East Street, Chaoyang District, Beijing 100015, China.

E-mail: 13911022130@163.com

Dr. Hui Zeng, Department of Institute of Infectious Diseases, Beijing Ditan Hospital, Capital Medical University, No.8 Jingshun East Street, Chaoyang District, Beijing 100015, China.

E-mail: zenghui@ccmu.edu.cn

\section{Introduction}

Hematological abnormalities are one of the most important complications in HIV-infected patients. In those with advanced HIV infection, anemia is the most common manifestation (1). The prevalence of anemia in the HIV-infected population varies between $18.9 \%$ and $65.5 \%$, dependent on setting and social-economic conditions (1-3); normocytic anemia is most common. Different pathogenic factors are associated with HIVrelated anemia, including opportunistic infections such malaria (4) and parvovirus B19 (5) or Penicilliosis 
marneffei ( 6 ) infection, administration of antiretroviral agents such as zidovudine (7), and myelosuppression by infiltrative malignancies (8) or infectious pathogens (6). Other mechanisms for HIV-related anemia included vitamin B12, folate, and iron deficiencies (9), and HIVdriven impairment of hematopoietic progenitor cells (10).

Anemia can cause negative physiological functioning, which results in poor quality of life. Some studies reported that in HIV-infected patients, anemia was associated with disease progression and poor prognosis (11). Moore et al. (12) demonstrated that treating anemia reduced the risk of death and improved prognosis, indicating the need for periodic screening for and treatment of anemia, especially among patients not yet started on combined antiretroviral therapy (cART). The prevalence of and risk factors for anemia vary remarkably in different regions in China due to different socioeconomic conditions. Shen et al. (13) reported that the overall prevalence of anemia among HIVinfected patients was $51.9 \%$ and that anemia was highly prevalent among Chinese adults newly diagnosed with HIV-infection, but that severe anemia was less prevalent in this population. Older age, lower CD4 count, and minority ethnicity are associated with an increased risk of anemia: Mijiti et al. (14) reported that $38.9 \%$ of HIV-infected patients in Xinjing Province, China, were anemic at the time of cART initiation, and that Uyghur ethnicity, female sex, lower CD4 count, lower body mass index (BMI), self-reported tuberculosis infection, and oral candidiasis were associated with a higher prevalence of anemia.

Despite the availability of cART in China (15), confirmatory anti-HIV antibody testing is often performed late, once HIV infection has progressed to AIDS and CD4 counts are low, as many people are unaware of HIV infection (16). Both clinically advanced disease and low CD4 counts are associated with an increased risk of anemia (17). In China, the prevalence of anemia varies markedly between different regions (3), and mild anemia is prone to be neglected in clinical work. The prevalence of and risk factors for anemia, and the association between anemia and prognosis in HIVinfected patients are not well documented in China. Therefore, in this study, we retrospectively studied the baseline, pre-cART prevalence of anemia; the risk factors associated with anemia; and its impact on mortality in HIV-infected patients in Beijing Ditan Hospital, the largest specialized hospital for HIV-infected patients in North China. Further, we analyzed the trends of anemia incidence over the study period, once patients were established on cART.

\section{Materials and Methods}

\subsection{Ethical considerations}

This retrospective observational cohort study was approved by the institutional review board of Beijing Ditan Hospital, the Capital Medical University, and complies with principles of the Declaration of Helsinki. Existing routine clinical and therapeutic data were anonymously used and were abstracted from the electronic medical records in Ditan Hospital; hence, the need for informed consent was waived.

\subsection{Patient selection}

We conducted the retrospective study in Beijing Ditan Hospital, the largest designated tertiary care hospital for HIV/AIDS in North China, from June, 2003 to December, 2015. Eligible participants were HIV-infected, confirmed by enzyme-linked immunosorbent assay (ELISA) and Western Blot testing; cART-naïve, ready to initiate treatment; and aged $\geq 18$ years. We excluded patients who received interferon or ribavirin, patients with cirrhosis, and pregnant women.

\subsection{Definitions and outcome}

Prior to receiving cART, routine baseline blood tests were performed. Anemia was diagnosed as a hemoglobin level $<110 \mathrm{~g} / \mathrm{L}$ (women) or $<120 \mathrm{~g} / \mathrm{L}$ (men). Anemia status was categorized as: mild (hemoglobin 90-109 g/ $\mathrm{L}$ [women] or 90-119 g/L [men]), moderate (60-89 g/L), and severe (hemoglobin $<60 \mathrm{~g} / \mathrm{L}$ ). Baseline leucopenia was diagnosed as a white cell count $<4.0$ cells $\times 10^{9} / \mathrm{L}$ and thrombocytopenia as a platelet count $<100 \times 10^{9} / \mathrm{L}$ in peripheral blood.

After cART initiation, follow-ups were scheduled at 2 nd week, $1^{\text {st }}$ month, $2^{\text {nd }}$ month, $3^{\text {rd }}$ month and every 3 month thereafter. At the time of follow-up, CD4 cell counts were routinely tested every 3 months, and viral load was tested every 6 months. The detail data about enrollment, dead cases and lost to follow-up were shown in Table supplement 1 (Table S1).

The primary outcome was death. The date of death was recorded in the electronic medical record system in Ditan Hospital, which helped to provide time from initial diagnosis to death.

The National Free Antiretroviral Treatment Program (NFATP) provides antiretroviral therapy and follow-up for HIV-infected patients in China (18), and 1-month antiretroviral regimens are provided to HIV-infected patients during first 3 months after initiation of cART, and after that, 3-month regimens are provided to patients, which helps control periodic follow-up rate in HIVinfected patients in China.

Clinical data about baseline evaluation, followup, lost to follow-up and dead cases are recorded in electronic medical records and provided to database in NFATP. Ditan Hospital is an observational sentinel for NFATP, which serves HIV-infected population in Beijing. The patients in our cohort are outpatients, who initiate antiretroviral therapy and receive follow-up in Ditan 
Hospital. Mortality was calculated due to unambiguous records in database in NFATP.

We also found some patients were withdrawal during follow-up, and Zhang et al. (19) reported that factors independently associated with a higher likelihood of missed visits included female gender, age $>60$ years, HIV transmission via injection drug use or plasma donation, baseline alanine aminotransferase $>100$ IU/ $\mathrm{L}$, and having more symptoms at antiretroviral therapy initiation.

\subsection{Data collection}

Study participants completed scheduled structured questionnaires, eliciting data on sociodemographic and clinical characteristics including sex, age, height, weight, transmission routes, World Health Organization (WHO) clinical stage, and trimethoprim/sulfamethoxazole (SMX-TMP) co-administration. BMI was calculated as weight $(\mathrm{kg})$ divided by the square of height $(\mathrm{m})$. Baseline laboratory tests were performed to measure CD4 count, HIV viral load, hemoglobin, white cell count, and platelet levels, and to detect hepatitis $\mathrm{B}(\mathrm{HBV})$ or $\mathrm{C}(\mathrm{HCV})$ virus infection.

\subsection{Statistical analysis}

Descriptive analysis was conducted, using frequency and percentages. Bar charts were used to illustrate the proportion of patients with mild, moderate, and severe anemia, stratified by CD4 count and outcome. Incidence rates were calculated as the number of cases of anemia per 100 person-years, and line charts were used to illustrate the trends in incidence of anemia during the follow-up period.

In this study, univariate logistic regression models were used to determine associations between anemia and the following variables: sex; age; HIV transmission route; WHO clinical stage; BMI; baseline CD4, white cell, and platelet counts; baseline and follow-up HIV viral load; SMZ-TMP co-administration; and baseline HBV/HCV co-infection. Statistically significant variables were fitted into a subsequent multivariate logistic regression models.

Cox proportional hazards models were used to evaluate the impact of anemia on mortality in HIVinfected patients. Kaplan-Meier survival curves were computed to evaluate the survival of HIV-infected patients with and without anemia. Log-rank testing was conducted to evaluate differences in cumulative survival between the two groups. All statistical analyses were performed using SPSS version 19.0 (SPSS Institute, Chicago IL, USA). Alpha was set to 0.05 , and 95\% confidence intervals (CI) were used.

\section{Results}

\subsection{Demographic and clinical characteristics}

From June, 2003 to December, 2015, we enrolled 3452 HIV-infected patients into our study. Table 1 describes their demographic and clinical characteristics. The median age of study subjects was 33.7 (range, 1883 ) years and $93.7 \%$ were men. Sexual contact was the most common route of transmission (3124 cases, $90.5 \%) ; 79.8 \%$ was due to homosexual contact ( 2756 cases) and $10.7 \%$ was due to extra-marital heterosexual contact (368 cases). Overall, 38.1\% of study subjects had a baseline CD 4 count $<200$ cells $\times 10^{9} / \mathrm{L}$.

\subsection{Prevalence of anemia, overall and stratified by CD4 count category}

The overall prevalence of anemia prior to initiating cART was $9.76 \%(n=337)$, with mild, moderate, and severe anemia observed in $7.6 \%(n=263), 1.9 \%(n=$ $66)$, and $0.2 \%(n=8)$ of patients, respectively (Table 1$)$. Among patients with CD4 cell counts of $\leq 50,51-199$, $200-349$, and $\geq 350 \times 10^{9} / \mathrm{L}$ the prevalence of anemia was $43.0 \%, 11.0 \%, 2.7 \%$, and $2.1 \%$, respectively (Figure 1 and Table 1).

\subsection{Predictors of anemia in HIV-infected patients}

As seen in Table 2, the multivariate logistic regression model indicated that female sex (odds ratio [OR]: 3.71, 95\% CI: $1.46-6.51, p=0.003$ ), age $40-59$ years (OR: 2.54, 95\% CI: $1.59-4.05, p<0.001)$, age $>60$ years (OR: 2.80, 95\% CI: 1.80-7.24, $p=0.034$ ), and BMI < $18.5 \mathrm{~kg} / \mathrm{m}^{2}$ (OR: 2.23 , 95\% CI: $1.31-3.79, p=0.003$, compared with normal BMI and overweight), were associated with increased odds of anemia. Laboratory tests indicated that baseline HIV viral load $>10^{5}$ copies/ mL (OR: 2.79, 95\% CI: 1.85-4.20, $p<0.001$ ), baseline CD4 count $\leq 50 \times 10^{9} / \mathrm{L}(\mathrm{OR}: 17.12,95 \%$ CI: $7.70-$ $38.06, p<0.001)$, and CD4 count 51-199 × 10\% $/$ L (OR: 2.81, 95\% CI: 1.32-5.99, $p=0.007)$ were risk factors for anemia. Anemia was not associated with route of HIV transmission, WHO clinical stage, baseline HIV viral load, SMZ-TMP co-administration, or baseline $\mathrm{HBV} / \mathrm{HCV}$ co-infection status.

\subsection{Mortality, stratified by CD4 count category and by anemia}

Overall, $1.3 \%(n=44)$ of the cohort died. Among patients with mild, moderate, and severe anemia, mortality was $7.2 \%$ (19 of 263), 10.6\% (7 of 66), and $12.5 \%$ ( 1 of 8 ), respectively (Table 1 ). Figure 2 displays mortality stratified by level of immune suppression (CD4 count category).

\subsection{Survival analysis}

The multivariate Cox regression model indicated that age 40-59 years (adjusted hazard ratio [AHR]: 5.76, 
Table 1. Baseline demographic, clinical, and laboratory characteristics of HIV-infected patients

\begin{tabular}{|c|c|c|c|c|}
\hline Characteristic & Total & Deaths & With anemia & Without anemia \\
\hline Total & $3,452(100)$ & $44(1.27)$ & $337(9.76)$ & $3,115(90.24)$ \\
\hline \multicolumn{5}{|l|}{ Sex } \\
\hline Male & $3,233(93.66)$ & $42(1.30)$ & $299(9.25)$ & $2,934(90.75)$ \\
\hline Female & $219(6.34)$ & $2(0.91)$ & $38(17.35)$ & $181(82.65)$ \\
\hline \multicolumn{5}{|l|}{ Age (years) } \\
\hline $18-39$ & $2,673(77.43)$ & $12(0.45)$ & $208(7.78)$ & $2,465(92.22)$ \\
\hline $40-59$ & $676(19.58)$ & $22(3.25)$ & $103(15.24)$ & $573(84.76)$ \\
\hline$\geq 60$ & $103(2.98)$ & $10(9.71)$ & $26(25.24)$ & $77(74.76)$ \\
\hline \multicolumn{5}{|c|}{ Transmission route } \\
\hline Sexual & $3,124(90.50)$ & $30(0.96)$ & $284(9.09)$ & $2,870(91.87)$ \\
\hline Transfusion & $98(2.84)$ & $8(8.16)$ & $27(27.55)$ & $71(72.45)$ \\
\hline Unknown & $230(6.63)$ & $6(2.61)$ & $26(11.30)$ & $174(75.65)$ \\
\hline \multicolumn{5}{|c|}{ WHO clinical stage } \\
\hline I & $2,536(73.46)$ & $16(0.63)$ & $165(6.51)$ & 2,371 (93.49) \\
\hline II & $212(6.14)$ & $3(1.42)$ & $14(6.60)$ & $198(93.40)$ \\
\hline III & $244(7.07)$ & $4(1.64)$ & $25(10.25)$ & $219(89.75)$ \\
\hline IV & $460(13.33)$ & $21(4.57)$ & $133(28.91)$ & $327(71.09)$ \\
\hline \multicolumn{5}{|l|}{ BMI $\left(\mathrm{kg} / \mathrm{m}^{2}\right)^{\mathrm{a}}$} \\
\hline $18.5-24$ & $1,823(67.10)$ & $15(0.82)$ & $182(9.98)$ & $1,641(90.02)$ \\
\hline$<18.5$ & $300(11.04)$ & $6(0.02)$ & $98(32.67)$ & $202(67.33)$ \\
\hline$\geq 24$ & $594(21.86)$ & $5(0.84)$ & $27(4.55)$ & $567(95.45)$ \\
\hline \multicolumn{5}{|c|}{$\mathrm{CD} 4$ count $\left(\times 10^{9} / \mathrm{L}\right)$} \\
\hline$\geq 350$ & $813(23.55)$ & $1(0.12)$ & $17(2.09)$ & $796(97.91)$ \\
\hline 200-349 & $1,325(38.38)$ & $7(0.53)$ & $36(2.72)$ & $1,289(97.28)$ \\
\hline $51-199$ & $879(25.46)$ & $16(1.82)$ & $97(11.04)$ & $782(88.96)$ \\
\hline$\leq 50$ & $435(12.60)$ & $20(4.60)$ & $187(42.99)$ & $248(57.01)$ \\
\hline \multicolumn{5}{|c|}{ HIV RNA level (copies/mL) } \\
\hline$<100,000$ & $2,306(74.75)$ & $16(0.69)$ & $87(3.77)$ & $2,219(96.23)$ \\
\hline$\geq 100,000$ & $779(25.25)$ & $12(1.54)$ & $178(22.85)$ & $601(77.15)$ \\
\hline \multicolumn{5}{|c|}{ White cell count $\left(\times 10^{9} / \mathrm{L}\right)$} \\
\hline$\geq 4.0$ & $2,894(83.84)$ & $28(0.97)$ & $180(6.22)$ & $2,714(93.78)$ \\
\hline$<4.0$ & $558(16.16)$ & $16(2.87)$ & $157(28.14)$ & $401(71.86)$ \\
\hline \multicolumn{5}{|c|}{ Platelet count $\left(\times 10^{9} / \mathrm{L}\right)$} \\
\hline$\geq 100$ & $3,315(96.03)$ & $33(1.00)$ & $292(8.81)$ & $3,023(91.20)$ \\
\hline$<100$ & $137(3.97)$ & $11(8.03)$ & $45(32.85)$ & $92(67.15)$ \\
\hline \multicolumn{5}{|c|}{ SMZ-TMP co-administration } \\
\hline No & $3,122(90.44)$ & $39(1.25)$ & $241(7.72)$ & $2,881(92.28)$ \\
\hline Yes & $330(9.56)$ & $5(1.52)$ & $96(29.09)$ & $234(70.91)$ \\
\hline \multicolumn{5}{|c|}{$\mathrm{HBV} / \mathrm{HCV}$ co-infection } \\
\hline No & $3,236(93.74)$ & $37(1.14)$ & $312(9.64)$ & $2,924(90.36)$ \\
\hline Yes & $216(6.26)$ & $7(3.24)$ & $25(11.57)$ & $191(88.43)$ \\
\hline \multicolumn{5}{|l|}{ Anemia } \\
\hline Mild & $263(7.62)$ & $19(7.22)$ & $263(100.0)$ & - \\
\hline Moderate & $66(1.91)$ & $7(10.61)$ & $66(100.0)$ & - \\
\hline Severe & $8(0.23)$ & $1(12.50)$ & $8(100.0)$ & - \\
\hline
\end{tabular}

Data are presented as $n(\%)$; WHO, World Health Organization; BMI, body mass index; SMZ-TMP, Trimethoprim/sulfamethoxazole; ${ }^{\mathrm{a}}$ Variable had missing values: $\mathrm{BMI}=735$; HIV RNA level $=367$.

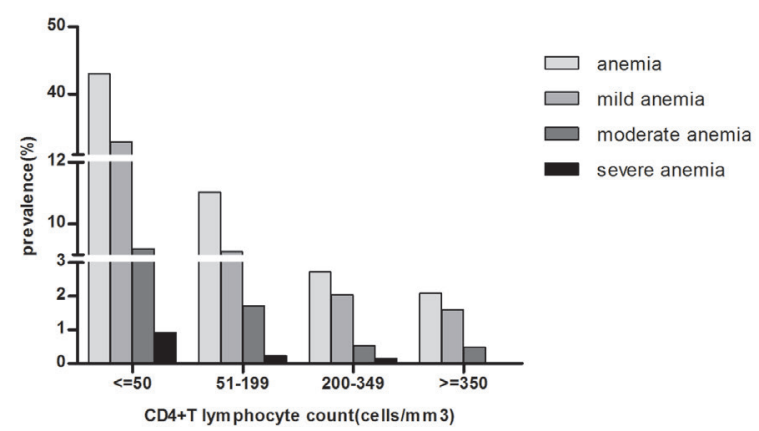

Figure 1. Prevalence of anemia in HIV-infected patients stratified by CD4 count category. The numbers of patients with CD4 counts of $\leq 50,51-199,200-349$, and $\geq 350 \times 10^{9} /$ $\mathrm{L}$ were $435,879,1,325$, and 813 , respectively. The number of cases of anemia among CD4 counts of $\leq 50,51-199,200-349$, and $\geq 350 \times 10^{9} / \mathrm{L}$ were $187,97,36$, and 17 , respectively.
95\% CI: 1.62-20.55, $p=0.007$ ), mild anemia (AHR: 7.46, 95\% CI: 1.48-37.50, $p=0.015)$, moderate anemia (AHR: 9.89, 95\% CI: 1.35-72.38, $p=0.024$ ), and severe anemia (AHR: 28.29, 95\% CI: 2.75-290.54, $p$ $=0.005)$ were associated with an increased hazard of mortality (Table 3 ). To clarify the effects of anemia on survival, Kaplan-Meier survival curves were plotted, stratified by presence or absence of anemia (Figure $3)$; log-rank testing demonstrated that there was a significant difference between the two groups $(p<0.05)$.

\subsection{Incidence of anemia, stratified by sex}

In this cohort, $79.8 \%$ of study participants were men infected with HIV through homosexual sexual contact. 
Table 2. Risk factors for anemia by logistic regression analysis in HIV-infected patients

\begin{tabular}{|c|c|c|c|c|c|}
\hline Characteristic & Anemia, $n(\%)$ & Univariate OR $(95 \% \mathrm{CI})$ & $p$ & Multivariate OR $(95 \% \mathrm{CI})$ & $p$ \\
\hline \multicolumn{6}{|l|}{ Sex } \\
\hline Male & $299(9.25)$ & 1 & - & 1 & - \\
\hline Female & $38(17.35)$ & $2.06(1.42-2.98)$ & $<0.001$ & $3.71(1.46-6.51)$ & 0.003 \\
\hline \multicolumn{6}{|l|}{ Age (years) } \\
\hline $18-39$ & $208(7.78)$ & 1 & - & 1 & - \\
\hline $40-59$ & $103(15.24)$ & $2.13(1.65-2.74)$ & $<0.001$ & $2.54(1.59-4.05)$ & $<0.001$ \\
\hline$\geq 60$ & $26(25.24)$ & $4.00(2.51-6.38)$ & $<0.001$ & $2.801(1.08-7.24)$ & 0.034 \\
\hline \multicolumn{6}{|c|}{ Transmission route } \\
\hline Sexual & $284(9.00)$ & 1 & - & 1 & - \\
\hline Transfusion & $27(27.55)$ & $3.99(2.53-6.28)$ & $<0.001$ & $1.59(0.55-4.58)$ & 0.395 \\
\hline Unknown & $26(13.07)$ & $1.46(0.94-2.26)$ & 0.089 & $1.16(0.52-2.56)$ & 0.719 \\
\hline \multicolumn{6}{|l|}{ WHO stage } \\
\hline I & $165(6.51)$ & 1 & - & 1 & - \\
\hline II & $14(6.60)$ & $1.02(0.58-1.77)$ & 0.942 & $0.58(0.20-1.67)$ & 0.310 \\
\hline III & $25(10.25)$ & $1.52(0.96-2.40)$ & 0.075 & $0.80(0.37-1.75)$ & 0.579 \\
\hline IV & $133(28.91)$ & $5.96(4.60-7.72)$ & $<0.001$ & $1.27(0.79-2.06)$ & 0.327 \\
\hline \multicolumn{6}{|l|}{ BMI $\left(\mathrm{kg} / \mathrm{m}^{2}\right)$} \\
\hline $18.5-24$ & $182(9.98)$ & 1 & - & 1 & - \\
\hline$<18.5$ & $98(32.67)$ & $4.23(3.06-5.84)$ & $<0.001$ & $2.23(1.31-3.79)$ & 0.003 \\
\hline$\geq 24$ & $27(4.55)$ & $0.50(0.32-0.78)$ & 0.002 & $0.62(0.35-1.10)$ & 0.098 \\
\hline \multicolumn{6}{|c|}{ Baseline CD4 count $\left(\times 10^{9} / \mathrm{L}\right)$} \\
\hline$\geq 350$ & $17(2.09)$ & 1 & - & 1 & - \\
\hline $200-349$ & $36(2.72)$ & $1.31(0.73-2.34)$ & 0.368 & $1.01(0.47-2.15)$ & 0.987 \\
\hline $51-199$ & $97(11.04)$ & $5.81(3.44-9.82)$ & $<0.001$ & $2.81(1.32-5.990)$ & 0.007 \\
\hline$\leq 50$ & 187 (42.99) & $35.31(21.06-59.18)$ & $<0.001$ & $17.12(7.70-38.06)$ & $<0.001$ \\
\hline \multicolumn{6}{|c|}{ Baseline HIV RNA level (copies/mL) } \\
\hline$<100,000$ & $87(3.77)$ & 1 & - & 1 & - \\
\hline$\geq 100,000$ & $178(22.85)$ & $5.51(4.19-7.23)$ & $<0.001$ & $2.79(1.85-4.20)$ & $<0.001$ \\
\hline \multicolumn{6}{|c|}{ Baseline white cell count $\left(\times 10^{9} / \mathrm{L}\right)$} \\
\hline$\geq 4.0$ & $180(6.22)$ & 1 & - & 1 & - \\
\hline$<4.0$ & $157(28.14)$ & $5.90(4.65-7.49)$ & $<0.001$ & $2.12(1.33-3.37)$ & 0.002 \\
\hline \multicolumn{6}{|c|}{ Baseline platelet count $\left(\times 10^{9} / \mathrm{L}\right)$} \\
\hline$\geq 100$ & $292(8.81)$ & 1 & - & 1 & - \\
\hline$<100$ & $45(32.84)$ & $5.06(3.48-7.38)$ & $<0.001$ & $1.71(0.79-3.72)$ & 0.175 \\
\hline \multicolumn{6}{|c|}{ SMZ-TMP co-administration } \\
\hline No & $241(7.72)$ & 1 & - & 1 & - \\
\hline Yes & $96(29.09)$ & $4.87(3.72-6.39)$ & $<0.001$ & $0.98(0.60-1.60)$ & 0.940 \\
\hline \multicolumn{6}{|c|}{ Baseline HBV/HCV co-infection } \\
\hline No & $312(9.64)$ & 1 & - & 1 & - \\
\hline Yes & $25(11.57)$ & $0.74(0.75-1.14)$ & 0.173 & $0.68(0.32-1.47)$ & 0.329 \\
\hline
\end{tabular}

OR, odds ratio; WHO, World Health Organization; BMI, body mass index; SMZ-TMP, Trimethoprim/sulfamethoxazole.

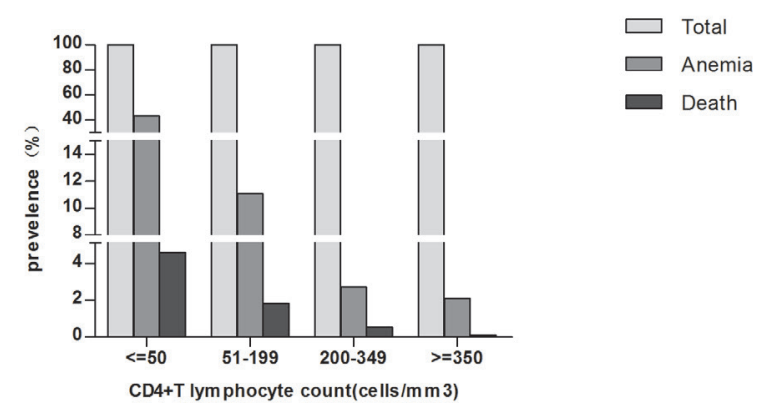

Figure 2. Mortality among HIV-infected patients stratified by CD4 count category. The number of deaths in the CD4 count categories $\leq 50,51-199,200-349$, and $\geq 350 \times 10^{9} / \mathrm{L}$ were $20,16,7$, and 1 , respectively.

Given that the risk factors for anemia differ by sex, we examined total and sex-specific incidence rates of anemia (Figure 4). The incidence of anemia in women was significantly higher than that in men $(p<0.05)$.

\section{Discussion}

Hematologic abnormalities are reportedly the most common complications of advanced HIV infection (20), with anemia being the most common hematologic abnormality. Anemia affects a large proportion of those with advanced-stage HIV-infection. Moreover, anemia is an independent risk factor for morbidity and mortality in HIV-infected patients $(11,15)$. The prevalence and incidence of anemia varies in different socioeconomic conditions and clinical settings. In Europe and North America, anemia was found in 35$65 \%$ of HIV-infected patients pre-cART $(21,22)$. Prevalence rates of $42.9 \%$ (3) and $18.9 \%$ (1) were reported in Ethiopia and in a rural Ugandan cohort, respectively. In a study conducted in China, Shen at al. (13) reported a prevalence of anemia of $51.9 \%$ in patients newly diagnosed with HIV infection. In our study, the prevalence of anemia was $9.76 \%$, lower than 
Table 3. Cox proportional hazard regression analysis of mortality in HIV-infected patients

\begin{tabular}{|c|c|c|c|c|}
\hline Characteristics & Univariate analysis $\mathrm{HR}(95 \% \mathrm{CI})$ & $p$ & Multivariate analysis AHR $(95 \% \mathrm{CI})$ & $p$ \\
\hline \multicolumn{5}{|l|}{ Sex } \\
\hline Male & 1 & - & 1 & - \\
\hline Female & $0.57(0.14-2.38)$ & 0.441 & $0.22(0.03-1.63)$ & 0.139 \\
\hline \multicolumn{5}{|l|}{ Age (years) } \\
\hline $18-39$ & 1 & - & 1 & 0 \\
\hline $40-59$ & $6.17(3.03-12.55)$ & $<0.001$ & $5.76(1.62-20.55)$ & 0.007 \\
\hline$\geq 60$ & $13.34(5.01-35.55)$ & $<0.001$ & $4.50(0.43-46.97)$ & 0.208 \\
\hline \multicolumn{5}{|l|}{ WHO Stage } \\
\hline I & 1 & - & 1 & - \\
\hline II & $0.91(0.21-4.03)$ & 0.904 & $0.81(0.18-3.55)$ & 0.774 \\
\hline III & $1.93(0.55-6.76)$ & 0.303 & $1.36(0.38-4.84)$ & 0.663 \\
\hline IV & $5.28(2.47-11.29)$ & $<0.001$ & $1.63(0.78-3.75)$ & 0.251 \\
\hline \multicolumn{5}{|l|}{ BMI $\left(\mathrm{kg} / \mathrm{m}^{2}\right)$} \\
\hline $18.5-24$ & 1 & - & 1 & - \\
\hline$<18.5$ & $2.84(1.03-7.86)$ & 0.044 & $0.86(0.16-4.66)$ & 0.865 \\
\hline$\geq 24$ & $1.30(0.33-3.20)$ & 0.956 & $1.55(0.36-6.65)$ & 0.556 \\
\hline \multicolumn{5}{|c|}{ Baseline CD4 count $\left(\times 10^{9} / \mathrm{L}\right)$} \\
\hline$\geq 350$ & 1 & - & 1 & - \\
\hline $200-349$ & $1.22(0.25-6.08)$ & 0.806 & $1.15(0.23-5.73)$ & 0.747 \\
\hline $51-199$ & $5.64(1.31-24.19)$ & 0.020 & $3.35(0.77-14.55)$ & 0.569 \\
\hline$\leq 50$ & $7.71(1.74-34.18)$ & 0.007 & $2.05(0.44-9.63)$ & 0.112 \\
\hline \multicolumn{5}{|c|}{ Baseline HIV RNA level (copies/mL) } \\
\hline$<100,000$ & 1 & - & 1 & - \\
\hline$\geq 100,000$ & $1.58(0.73-3.43)$ & 0.249 & $0.71(0.21-2.36)$ & 0.575 \\
\hline \multicolumn{5}{|l|}{ Anemia } \\
\hline Mild & $13.50(6.65-27.42)$ & $<0.001$ & $7.46(1.48-37.50)$ & 0.015 \\
\hline Moderate & $20.75(8.35-51.59)$ & $<0.001$ & $9.89(1.35-72.38)$ & 0.024 \\
\hline Severe & $19.13(2.50-149.34)$ & 0.004 & $28.29(2.75-290.54)$ & 0.005 \\
\hline
\end{tabular}

HR, hazard ratio; AHR, adjusted hazard ratio; WHO, World Health Organization; BMI, body mass index.

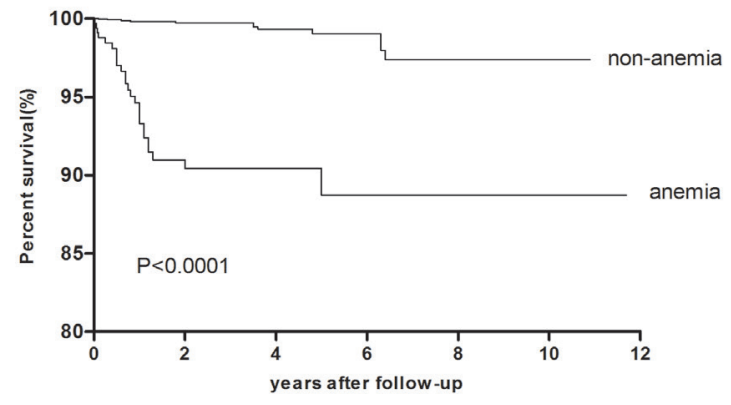

Figure 3. Survival curve for HIV-infected patients with or without anemia. Log-rank test $p<0.001$.

observed in previous studies. This low prevalence was remarkable, and may be explained by our study setting: First, patients were managed in a hospital-based setting (23). This has some advantages over community-based treatment models (24) that are commonly applied in China, including timely diagnosis of HIV infection and early detection of anemia. Healthcare workers in the hospital-based HIV treatment model formed a coordinated team to provide support to individuals with high-risk exposure or to cART-naïve patients (23), including counseling, earlier HIV testing of individuals at high-risk, periodic CD4 cell count measurement, routine blood tests, and timeous cART initiation. These interventions significantly reduce morbidity

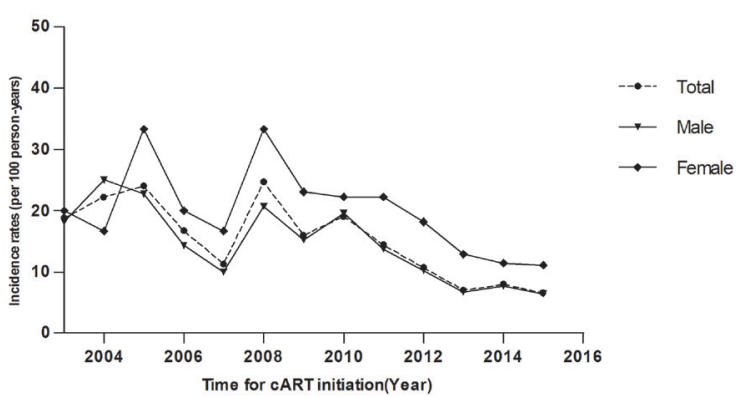

Figure 4. Incidence of anemia in HIV-infected patients, stratified by sex. Incidence rates of anemia in female HIVinfected patients were significantly higher than those in male patients $(p<0.05)$.

and mortality. Second, we included a high proportion of urban residents. Ditan Hospital, an observational sentinel for the National Free Antiretroviral Treatment Program (NFATP) in China (23), serves urban residents in Beijing. Urban study subjects may have received more adequate information about nutrition and routine blood testing than their rural counterparts. Third, cART was initiated at higher CD4 count thresholds than in previous studies. The guidelines for the use of antiretroviral agents in China (25) recommend initiation of cART at a CD4 count $<350 \times 10^{9} / \mathrm{L}$, or a CD4 count $>350 \times 10^{9} / \mathrm{L}$ certain clinical criteria are met. Some studies documented that a CD4 count $<200 \times 10^{9} / \mathrm{L}$ 
was associated with myelosuppression and anemia (20). Thus, initiating cART at a higher CD4 count threshold reduces the risk of anemia.

Several mechanisms contribute to the pathophysiology of anemia in HIV-infected patients, including increased destruction and decreased or inadequate production of red blood cells $(13,26)$. Alexaki et al. (27) documented that anemia occurred in the absence of opportunistic infections, malignancies, and chemotherapy in HIV-infected patients; hence, HIV itself must be involved in the pathophysiology of hematological abnormalities. Anemia may be associated with three HIV-driven mechanisms (10): i) impaired proliferation of hematopoietic progenitor cells, ii) inhibition of differentiation of hematopoietic progenitor cells into cell lineages, and iii) impairment of stromal cells. Moses et al. (28) demonstrated that stromal cells in the microenvironment of the bone morrow can be infected with HIV, resulting in dysregulation of cytokine expression and decreased red blood cell production. Erythropoietin is a glycoprotein hormone that controls erythropoiesis. Some studies demonstrated erythropoietin resistance as a pathophysiological phenomenon in HIVinfected patients (9), in which circulating auto-antibodies against endogenous erythropoietin blunted the normal physiological cytokine response to anemia. Vanasse et al. (29) reported that erythropoietin resistance was found in the hematopoietic stem cells of aging individuals, and that senescence was related to enhanced expression of inflammatory cytokines that positively regulated erythropoietin resistance, leading to anemia in older age. Older age was found to be an independent risk factor for anemia in this study.

The most statistically significant risk factors for anemia in HIV-infected patients in this study were age $\geq 40$ years, female sex, BMI $<18.5 \mathrm{~kg} / \mathrm{m}^{2}$, and baseline CD4 count $\leq 199 \times 10^{9} / \mathrm{L}$. The higher prevalence of anemia in women might be due to menstrual blood loss that drains iron stores. Lower BMI is related to malnutrition and nutrient deficiencies, including deficiencies of vitamin B12, folate, and iron, which directly result in anemia. Similar to prior findings $(3,20)$, our results found a strong independent association between CD4 count $\leq 199 \times 10^{9} / \mathrm{L}$ and anemia; this association was most pronounced in those with a CD4 count $<50 \times 10^{9} / \mathrm{L}$. We also demonstrated that higher baseline HIV viral loads were associated with anemia. Sullivan et al. (30) demonstrated that, as HIV infection progressed and immune status deteriorated, HIV viral loads increased, causing cytokine-mediated myelosuppression and anemia.

Although SMX-TMP administration may cause drug-induced aplastic anemia, several studies $(30,31)$ failed to find this association. Keisu et al. (31) found that SMX-TMP induced anemia, but that this effect was sporadic. Conversely, Sullivan et al. (30) demonstrated a negative association between SMX-TMP use and anemia, explained by the protective effect of SMX-TMP in preventing infections caused by some opportunistic pathogens (such as Mycobacterium avium complex) that can contribute to the development of anemia. In the present study, we failed to demonstrate an association between SMX-TMP administration and anemia. We also we failed to demonstrate an association between $\mathrm{HIV} / \mathrm{HCV}$ or HIV/HBV co-infection and anemia. Such co-infections can cause anemia due to interferonassociated antiviral therapy or decompensated cirrhosis. That we did not observe this is most likely explained by our exclusion of those receiving interferon or ribavirin and of those diagnosed with cirrhosis.

In the multivariate Cox regression analysis, we found that anemia was the most statistically significant predictor of mortality in HIV-infected patients. Similarly, Santiago-Rodríguez et al. (17) reported that anemia was the strongest predictor of mortality in a cohort of HIV-infected Hispanics, and that the risk of mortality was proportional to the severity of anemia. In a study involving a large urban HIV clinical practice in the US, Moore et al. (32) indicated that the development of anemia was associated with decreased survival, independent of other prognostic factors. In addition, Mocroft et al. (33) demonstrated that a $10 \mathrm{~g} /$ $\mathrm{L}$ decrease in most recent hemoglobin level increased the hazard of death by $57 \%$, implying that prophylactic measures against anemia should be instituted in HIVinfected patients with CD4 counts $<200 \times 10^{9} / \mathrm{L}$ or in patients with higher HIV viral loads. Such prophylactic measures would include vitamin B12, folate, and iron supplementation, and avoidance of myelosuppressive drugs such as zidovudine. The Chinese national HIV treatment guidelines (25) recommend the use of zidovudine in first-line cART regimens. However, zidovudine should be avoided when initiating cART in patients with the above-mentioned anemia-related risk factors, based on baseline evaluation prior to treatment initiation. Some studies have indicated (3) that use of cART improves anemia, suggesting that cART should be initiated as soon as possible in HIV-infected patients with anemia.

Our study has some limitations. First, this was a retrospective observational study; hence, it was subject to the potential biases inherent in the use of observational data. Second, the study sample selection influenced the findings. The study population comprised urban residents in Beijing, who were treated within a hospital-based HIV treatment model. This limits the generalizability of our findings, as the study sample does not represent the HIV-infected population in China more generally, many of whom are treated within community-based treatment models. Third, data were obtained from baseline evaluation prior to initiating cART. This impeded us from elucidating associations between anemia and variables that change over time.

In summary, the overall prevalence of anemia 
in cART-naïve patients was $9.76 \%$ and mild anemia was most common. Anemia was associated with female sex, older age, lower BMI, lower baseline CD4 count, and baseline higher viral load, but was not associated with route of HIV transmission, WHO clinical stage, baseline HIV viral load, SMZ-TMP coadministration, or baseline $\mathrm{HBV} / \mathrm{HCV}$ co-infection. Anemia was associated with an increased risk of mortality in cART-naïve patients. These findings should be used to promote awareness among physicians to identify anemia early and to prioritize prevention and intervention strategies for anemia in HIV-infected patients.

\section{Acknowledgements}

We acknowledge the work of HIV health care providers for their diagnosis, nursing, and treatment of HIVinfected patients in Ditan Hospital. We acknowledge the work of social workers and volunteers in Beijing Red Ribbon who provide counseling, adherence interventions and resolving psychosocial issues for HIV/AIDS patients.

Support for this work was provided by: 1) Healthcare Talent Training Program in Beijing Health System (grant 2015-3-105); 2) the National Natural Science Fund The study of T-cell repertoire diversity in AIDS patients based on the restoration of thymic function (grant 81371804); 3) The Capital Health Research and Development of Special (grant 2014-2-2173); and 4) Beijing Municipal Administration of Hospitals' Youth Programme (No. QML20151701)

The funders had no role in study design, data collection and analysis, decision to publish, or preparation of the manuscript.

\section{References}

1. Mugisha JO, Shafer LA, Van der Paal L, Mayanja BN, Eotu H, Hughes P, Whitworth JA, Grosskurth H. Anaemia in a rural Ugandan HIV cohort: Prevalence at enrolment, incidence, diagnosis and associated factors. Trop Med Int Health. 2008; 13:788-794.

2. Dikshit B, Wanchu A, Sachdeva RK, Sharma A, Das R. Profile of hematological abnormalities of Indian HIV infected individuals. BMC Blood Disord. 2009; 9:5.

3. Assefa M, Abegaz WE, Shewamare A, Medhin G, Belay M. Prevalence and correlates of anemia among HIV infected patients on highly active anti-retroviral therapy at Zewditu Memorial Hospital, Ethiopia. BMC Hematol. 2015; 15:6.

4. Naing C, Sandhu NK, Wai VN. The effect of malaria and HIV co-infection on anemia: A meta-analysis. Medicine (Baltimore). 2016; 95:e3205.

5. Ferry T, Hirschel B, Dang T, Meylan P, Delhumeau C, Rauch A, Weber R, Elzi L, Bernasconi E, Schmid P, Calmy A; Swiss HIV Cohort Study. Infrequent replication of parvovirus B19 and erythrovirus genotypes 2 and 3 among HIV-infected patients with chronic anemia. Clin Infect Dis. 2010; 50:115-118.

6. Qiu Y, Zhang J, Liu G, Zhong X, Deng J, He Z, Jing B. Retrospective analysis of 14 cases of disseminated Penicillium marneffei infection with osteolytic lesions. BMC Infect Dis. 2015; 15:47.

7. Akilimali PZ, Kashala-Abotnes E, Musumari PM, Kayembe PK, Tylleskar T, Mapatano MA. Predictors of persistent anaemia in the first year of antiretroviral therapy: A retrospective cohort study from Goma, the Democratic Republic of Congo. PLoS One. 2015; 10:e0140240.

8. Bidmos MA, Joubert S, van Jaarsveld MF, Louw VJ. Plasma cell leukaemia and HIV co-infection: Profile of patients and experience at Universitas Academic Hospital in Bloemfontein, South Africa. Int J Hematol. 2013; 98:672-680.

9. Redig AJ, Berliner N. Pathogenesis and clinical implications of HIV-related anemia in 2013. Hematology Am Soc Hematol Educ Program. 2013; 2013:377-381.

10. Gibellini D, Clò A, Morini S, Miserocchi A, Ponti C, Re MC. Effects of human immunodeficiency virus on the erythrocyte and megakaryocyte lineages. World J Virol. 2013; 2:91-101.

11. Moyle G. Anaemia in persons with HIV infection: Prognostic marker and contributor to morbidity. AIDS Rev. 2002; 4:13-20.

12. Moore RD. Anemia and human immunodeficiency virus disease in the era of highly active antiretroviral therapy. Semin Hematol. 2000; 37(4 Suppl 6):18-23.

13. Shen Y, Wang Z, Lu H, Wang J, Chen J, Liu L, Zhang $\mathrm{R}$, Zheng Y. Prevalence of anemia among adults with newly diagnosed HIV/AIDS in China. PLoS One. 2013; 8:e73807.

14. Mijiti P, Yuexin Z, Min L, Wubuli M, Kejun P, Upur H. Prevalence and predictors of anaemia in patients with HIV infection at the initiation of combined antiretroviral therapy in Xinjiang, China. Int J STD AIDS. 2015; 26:156-164.

15. Zhang F, Dou Z, Ma Y, Zhang Y, Zhao Y, Zhao D, Zhou S, Bulterys M, Zhu H, Chen RY. Effect of earlier initiation of antiretroviral treatment and increased treatment coverage on HIV-related mortality in China: A national observational cohort study. Lancet Infect Dis. 2011; 11:516-524

16. Xiao J, Gao G, Li Y, Zhang W, Tian Y, Huang Y, Su W, Han N, Yang D, Zhao H. Spectrums of opportunistic infections and malignancies in HIV-infected patients in tertiary care hospital, China. PLoS One. 2013; 8:e75915.

17. Santiago-Rodríguez EJ, Mayor AM, Fernández-Santos DM, Ruiz-Candelaria Y, Hunter-Mellado RF. Anemia in a cohort of HIV-infected Hispanics: Prevalence, associated factors and impact on one-year mortality. BMC Res Notes. 2014; 7:439.

18. Zhang F, Haberer JE, Wang Y, Zhao Y, Ma Y, Zhao D, Yu L, Goosby EP. The Chinese free antiretroviral treatment program: Challenges and responses. AIDS. 2007; 21:S143-148.

19. Zhang Y, Dou Z, Sun K, Ma Y, Chen RY, Bulterys M, Zhao Y, Zhu H, Liu Z, Zhang F. Association between missed early visits and mortality among patients of china national free antiretroviral treatment cohort. J Acquir Immune Defic Syndr. 2012; 60:59-67.

20. Kyeyune R, Saathoff E, Ezeamama AE, Löscher T, Fawzi W, Guwatudde D. Prevalence and correlates of cytopenias in HIV-infected adults initiating highly active 
antiretroviral therapy in Uganda. BMC Infect Dis. 2014; 14:496.

21. Mocroft A, Kirk O, Barton SE, Dietrich M, Proenca $\mathrm{R}$, Colebunders R, Pradier C, dArminio Monforte A, Ledergerber B, Lundgren JD. Anaemia is an independent predictive marker for clinical prognosis in HIV-infected patients from across Europe. EuroSIDA study group. AIDS. 1999; 13:943-950.

22. Harris RJ, Sterne JA, Abgrall S, et al. Prognostic importance of anaemia in HIV type-1-infected patients starting antiretroviral therapy: Collaborative analysis of prospective cohort studies. Antivir Ther. 2008; 13:959967.

23. Xiao J, Han N, Yang D, Zhao HX. Lower mortality in persons infected with HIV receiving antiretroviral treatment in a hospital-based model: An observational cohort study. Future Virol. 2014; 9:363-372.

24. Zhang F, Dou Z, Yu L, Xu J, Jiao JH, Wang N, Ma Y, Zhao Y, Zhao H, Chen RY. The effect of highly active antiretroviral therapy on mortality among HIV-infected former plasma donors in China. Clin Infect Dis. 2008; 47:825-833.

25. Zhang F, editor. National free HIV antiretroviral treatment handbook. 3rd ed. Beijing, China: People's Medical Publishing House. 2012; p235. (in Chinese)

26. Meidani M, Rezaei F, Maracy MR, Avijgan M, Tayeri K. Prevalence, severity, and related factors of anemia in HIV/AIDS patients. J Res Med Sci. 2012; 17:138-42.

27. Alexaki A, Wigdahl B. HIV-1 infection of bone marrow hematopoietic progenitor cells and their role in trafficking and viral dissemination. PLoS Pathog. 2008; 4:e1000215.

28. Moses A, Nelson J, Bagby GC. The influence of human immunodeficiency virus-1 on hematopoiesis. Blood. 1998; 91:1479-1495.

29. Vanasse GJ, Berliner N. Anemia in elderly patients: An emerging problem for the 21st century. Hematology Am Soc Hematol Educ Program. 2010:271-275.

30. Sullivan PS, Hanson DL, Chu SY, Jones JL, Ward JW. Epidemiology of anemia in human immunodeficiency virus (HIV)-infected persons: Results from the multistate adult and adolescent spectrum of HIV disease surveillance project. Blood. 1998; 91:301-308.

31. Keisu M, Wiholm BE, Palmblad J. Trimethoprimsulphamethoxazole associated blood dyscrasias. Ten years' experience of the Swedish spontaneous reporting system. J Intern Med.1990; 228:353-360.

32. Moore RD, Keruly JC, Chaisson RE. Anemia and survival in HIV infection. J Acquir Immune Defic Syndr Hum Retrovirol. 1998; 19:29-33.

33. Mocroft A, Kirk O, Barton SE, Dietrich M, Proenca $\mathrm{R}$, Colebunders R, Pradier C, dArminio Monforte A, Ledergerber B, Lundgren JD. Anaemia is an independent predictive marker for clinical prognosis in HIV-infected patients from across Europe. EuroSIDA study group. AIDS. 1999; 13:943-950.

(Received August 24, 2016; Revised November 8, 2016; Accepted November 18, 2016)

Supplemental Table

Table S1: Clinical data about enrollment, dead cases and lost to follow-up in our cohort

\begin{tabular}{lccc}
\hline $\begin{array}{l}\text { Time for cART } \\
\text { initiation (year) }\end{array}$ & $\begin{array}{c}\text { Enrollment } \\
\text { (cases) }\end{array}$ & $\begin{array}{c}\text { Deaths } \\
\text { (cases) }\end{array}$ & $\begin{array}{c}\text { Lost to follow-up } \\
\text { (cases) }\end{array}$ \\
\hline 2003 & 16 & 0 & 0 \\
2004 & 18 & 0 & 0 \\
2005 & 25 & 0 & 0 \\
2006 & 12 & 1 & 1 \\
2007 & 62 & 2 & 0 \\
2008 & 73 & 0 & 2 \\
2009 & 138 & 2 & 5 \\
2010 & 142 & 6 & 4 \\
2011 & 312 & 7 & 16 \\
2012 & 422 & 7 & 20 \\
2013 & 598 & 9 & 37 \\
2014 & 630 & 4 & 51 \\
2015 & 1,004 & 6 & 126 \\
\hline
\end{tabular}

cART, combination antiretroviral therapy. 